\title{
REVIEW
}

\section{Thyroid cancer in the age of COVID-19}

\author{
Venessa H M Tsang1,2,*, Matti Gild 1,2,3,*, Anthony Glover ${ }^{2,4}$, Roderick Clifton-Bligh 1,2,3 and Bruce G Robinson ${ }^{1,2,3}$ \\ 1Department of Endocrinology, Royal North Shore Hospital, St Leonards, Sydney, Australia \\ 2Sydney Medical School, Faculty of Medicine and Health, University of Sydney, Sydney, Australia \\ ${ }^{3}$ Cancer Genetics Laboratory, Kolling Institute of Medical Research, Sydney, Australia \\ ${ }^{4}$ Department of Endocrine Surgery, Royal North Shore Hospital, St Leonards, Sydney, Australia
}

Correspondence should be addressed to V H M Tsang: venessa.tsang@sydney.edu.au

*(V H M Tsang and M Gild contributed equally to this work)

\begin{abstract}
COVID-19 has modified the way we practice medicine. For thyroid cancer, there have been several significant impacts. First, the diagnosis has been delayed due to social isolation, reduced access to investigations and staff redeployment. Secondly, treatment planning has needed to take into account the risk to patients and/or staff of nosocomial transmission of the virus. Finally, there are some specific concerns with respect to interactions between the virus, its treatments and cancer. This mini-review aims to address each of these impacts and to provide some guidance and confidence to our patients and colleagues during this challenging time.
\end{abstract}

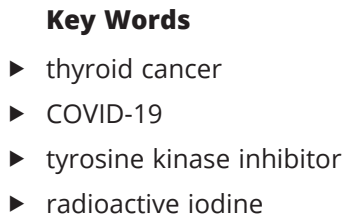

Endocrine-Related Cancer (2020) 27, R407-R416

\section{Introduction}

COVID-19 has quickly overwhelmed medical practice, albeit that most cases will recover uneventfully. The risk of death from COVID-19 is clearly related to older age and the presence of key comorbidities (Wang et al. 2020). Many patients with thyroid cancer will have these highrisk features; and many thyroid cancer specialists may also be deemed, vulnerable workers. Our usual algorithms of care based upon risk-stratified treatment modalities have acquired the ordinal variable of COVID-19 risk. Ordinarily, the choice for treatment of differentiated thyroid cancer is straightforward with surgery at the earliest opportunity followed, where indicated, by radioactive iodine (I $\left.{ }^{131}\right)$. Now, however, the risk of morbidity or mortality from thyroid cancer competes against the risk of COVID-19 exposure (to patients and staff) in medical settings and the availability of operative and post-operative care.

Early data from China suggests that COVID19 per se does not worsen the outcome of cancer, but as the pandemic continues, with investigations and treatment delay, morbidity and mortality from thyroid cancer may increase (Liang et al. 2020). Experience from other disasters is informative and may predict outcomes for thyroid cancer patient. Following Hurricane Katrina, breast cancer patients had a 15\% increase in mortality compared to matched patients at the same stage, which remained significant after adjustment for sociodemographic characteristics and cancers stage (Bell et al. 2020). A meta-analysis looking at the impact of natural disasters to oncology care identified infrastructure disruptions, health care workforce disruptions including delay in medical training, disruption to follow up, and medication stock shortages to be factors contributing to disruption in continuity of oncology care (Man et al. 2018). Although we lack much of the data required to best manage each cancer scenario, some generic principles have at least become apparent over the past few months.

In this review, we discuss some clinical challenges that clinicians could consider during this pandemic.
C) 2020 Society for Endocrinology Published by Bioscientifica Ltd. Printed in Great Britain 
A

Outpatient Clinic 2019 and 2020

mace to face $(2019=2111,2020=618)$ BTotal telehealth $(2019=56,2020=1561)$

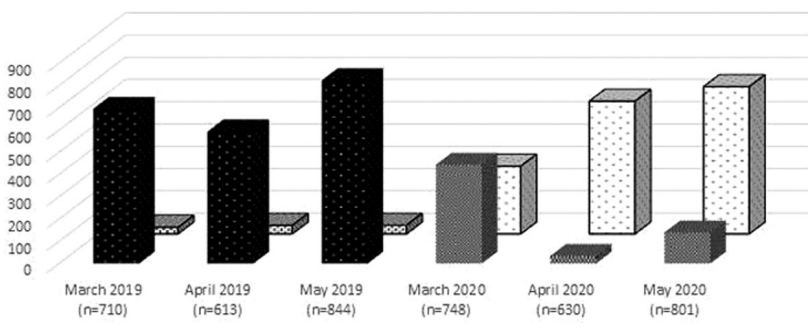

B Fine Needle Blopsy 2019 vs 2020

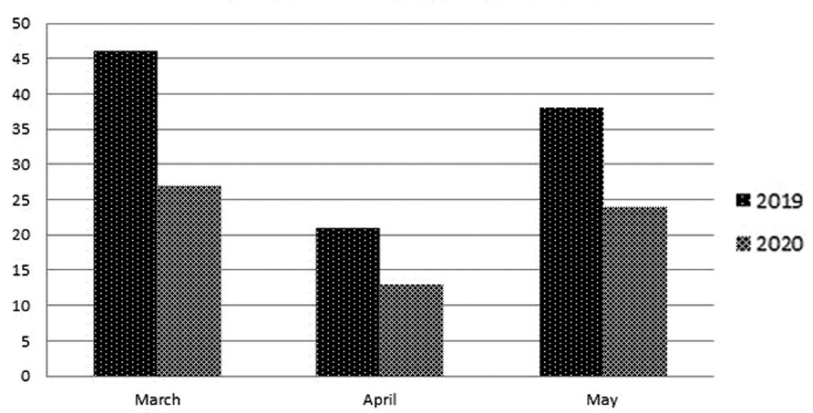

C I-131 Ablation Numbers 2019 vs 2020

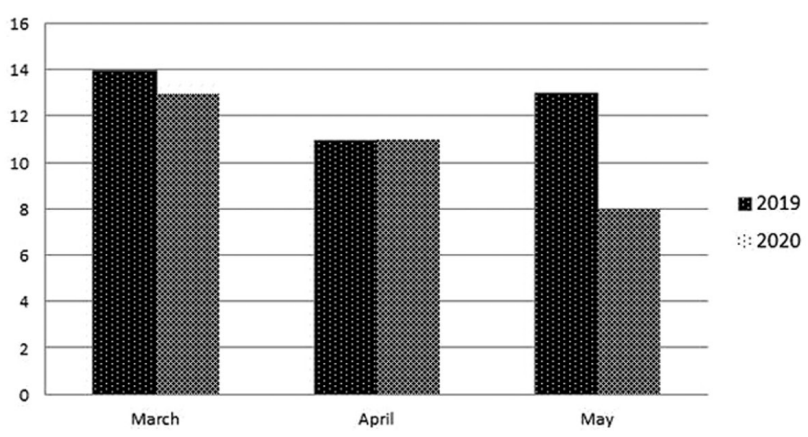

\section{Figure 1}

Impact of COVID-19 on outpatient clinic presentations, ultrasound-guided fine needle biopsy, and in-patient radioactive iodine ablation numbers at Royal North Shore Hospital, Sydney Australia. (A) The numbers of patients presenting for outpatient review via face to face and telehealth consultation (phone and video), at the Department of Endocrinology, Royal North Shore Hospital (RNSH), Sydney, Australia, in March, April, and May, in 2019 compared to 2020. Numbers in 2019. Though the total numbers of patients seen on all platforms, in $2019(n=2167)$ and 2020 $(n=2179)$ are the same in these two periods, the majority of patients were seen face to face in 2019, and via telehealth in 2020. (B) The numbers of patients undergoing ultrasound-guided fine needle biopsy aspirate in 2019 compared to 2020, in March, April and May at RNSH. The lower numbers in April in 2019 and 2020 likely reflect holidays during this period. Despite this, there has been a consistent reduction in numbers in 2020 compared to 2019, at 59\% for March, 62\% for April, and 63\% for May in 2020. (C) Numbers of patients having inpatient admission for radioactive iodine ablation in 2019 compared to 2020 at RNSH. Numbers are mostly maintained in March 93\% and April 100\% but reduced to $62 \%$ in April.

(c) 2020 Society for Endocrinology Published by Bioscientifica Ltd. Printed in Great Britain
We will reference experience with other coronaviruses where possible but the scale of COVID-19 is unprecedented and published experience is limited.

\section{Effect of COVID-19 risk mitigation strategies on thyroid cancer diagnosis}

\section{Delay in thyroid cancer diagnosis due to fewer medical assessments}

Social distancing and/or social isolation are now recognized as two of the most important protections against the spread of COVID-19 (Koo et al. 2020). However, both have resulted in changes to usual medical care. Within primary care, there was a rapid transfer form face-to-face consultation to telehealth from March 2020. Health care systems developed strategies to assess patients remotely (Greenhalgh et al. 2020, Kidd 2020) with greater than $80 \%$ of all consultations becoming virtual in published series (Gilbert et al. 2020). While clinicians and patients have been reasonably satisfied with video consultations, assessment for thyroid nodules or cancer recurrence is inadequate without physical examination and ultrasound (Greenhalgh et al. 2020, Hollander \& Carr 2020). Similarly, availability of fine needle biopsies for thyroid nodules has been restricted by concerns about COVID-19 (Huang et al. 2020a, Kooraki et al. 2020). Since fewer than $10 \%$ of all thyroid nodules will be malignant (Haugen et al. 2016), it has been reasonable to delay most thyroid biopsies during the pandemic, except for those nodules with highly concerning sonographic features as per TIRADS scoring system (Grant et al. 2015), or clinical features of obstruction (Huang et al. 2020a, Vrachimis et al. 2020).

Our own experience of the impact of COVID-19 on clinical practice is shown in Fig. 1; most of our consultations from March have been by telehealth, driven in part by institutional policy (Fig. 1A); whereas only $4.9 \%$ of consultations in 2019 was via telehealth, for the same period in 2020 it was $72 \%$ of consultations (41\% in March, 95\% in April, and 83\% in May), despite similar total consultation numbers $(2019 n=2167,2020$ $n=2179$ ). There has been a considerable decline in the number of thyroid biopsies performed in this time period (Fig. 1B); only 59\%, $62 \%$ and $63 \%$ of biopsies were being done in March, April, and May 2020 compared to 2019. Nevertheless, to date, we have been able to maintain our treatment for high-risk thyroid cancers, including I131 ablation for March (93\%) and April (100\%) but a 
slight decline in May (62\%) (Fig. 1C). Urgent surgery for proven thyroid cancer has not been delayed, with similar numbers in 2019 and 2020 (73\% of cases in April 2020 compared to 2019). Table 1 offers a proposed matrix for the management of thyroid cancer during COVID-19 based on our experience and the current risk level for local COVID-19 community transmission, including how to screen patients, triaging treatment including surgery, I-131, and systemic treatment, and outpatient follow up.

\section{Effect of COVID-19 risk mitigation strategies on thyroid cancer treatment}

\section{Balancing timing of cancer treatment against the risk of COVID-19 exposure (to patients and healthcare workers) in medical settings}

Thyroid cancer outcomes vary widely according to patient age, gender, histological subtype, extrathyroidal extension, nodal involvement and the presence or absence of distant metastases (Grant et al. 2015, Cabanillas et al. 2016). It is arguable that most papillary thyroid cancers occurring in younger subjects (e.g. $<50$ years) would not suffer from a delay in either diagnosis or treatment for the duration of the COVID-19 pandemic (Perrier et al. 2018); whereas treatment of advanced thyroid cancers may be time-critical particularly in the presence of airway compromise (Cabanillas et al. 2019). Where patients have space occupying lesions within the brain or spinal cord, extensive lung metastases, or neck lesions in close proximity to the trachea, prompt surgical, and systemic treatment may be time critical. This would include, where appropriate, $\mathrm{I}^{131}$, external beam radiotherapy (ERBT), and tyrosine kinase inhibitor (TKI) therapy. The benefit of these treatments has to be balanced against the risk of nosocomial transmission within the hospital setting. During the peak of the pandemic, where COVID-19 transmission rates were high, the significant risk of contracting COVID-19 during hospitalisation entails that treatment is justified if there is likely imminent progression. The utilisation of resources for patients to be admitted and use of personal protective equipment (PPE) to complete treatment is an additional consideration. In particular, in the aerosol generating head and neck surgeries, there is increased risk for health care workers (HCW) for contract COVID-19 and increased PPE is required to reduce HCW transmission (Couloigner et al. 2020, Cui et al. 2020, Kowalski et al. 2020, Mick \& Murphy 2020).

Where possible, oncology surgery has continued, but options, where this is not possible, include active surveillance; deferring those who have the stable disease who cannot undergo immediate surgery; and increasing PPE for patients who must undergo treatment (Huang et al. 2020b). Triaging of resources puts an additional strain on the clinicians and patients, and may need to be performed by a separate committee, to balance public health concerns and adequate management of thyroid cancer (Civantos et al. 2020). Balancing the need for surgery with the risk of both the patient and staff to asymptomatic COVID-19 needs to be carefully assessed (von Lilienfeld-Toal et al. 2020).

Table 1 Proposed matrix for management of thyroid cancer during COVID-19.

\begin{tabular}{|c|c|c|c|c|c|}
\hline Risk level* & Screening & Surgery & |131 & $\begin{array}{l}\text { Systemic } \\
\text { treatment }\end{array}$ & Follow up \\
\hline Low & $\begin{array}{l}\text { As per usual protocol. } \\
\text { Consideration of } \\
\text { minimising repeat } \\
\text { biopsies and FNA in } \\
\text { non-suspicious } \\
\text { nodules }\end{array}$ & $\begin{array}{l}\text { Consider delay in surgery if } \\
\text { possible, with operating } \\
\text { theatre rationalisation } \\
\text { and reduced use of } \\
\text { non-critical AGP (e.g. VCC) }\end{array}$ & $\begin{array}{l}\text { Adjuvant, recurrence and } \\
\text { palliative treatment as per } \\
\text { usual guidelines, } \\
\text { consideration of delaying } \\
\text { adjuvant treatment in low } \\
\text { risk cases }\end{array}$ & $\begin{array}{l}\text { As per usual } \\
\text { guidelines }\end{array}$ & $\begin{array}{l}\text { Telemedicine } \\
\text { preferred but } \\
\text { face-to-face } \\
\text { consultation } \\
\text { acceptable }\end{array}$ \\
\hline Medium & $\begin{array}{l}\text { Reduction in USS and } \\
\text { FNA to minimise } \\
\text { health care services } \\
\text { interaction }\end{array}$ & $\begin{array}{l}\text { All non-urgent elective } \\
\text { surgery postponed. Only } \\
\text { cases likely to cause } \\
\text { morbidity within } 30 \text { days } \\
\text { indicated (category 1) }\end{array}$ & $\begin{array}{l}\text { Continuation of treatment } \\
\text { for recurrence or } \\
\text { metastatic PTC }\end{array}$ & $\begin{array}{l}\text { Metastatic DTC, } \\
\text { all PDTC, all } \\
\text { MTC, all ATC to } \\
\text { receive usual } \\
\text { care }\end{array}$ & $\begin{array}{l}\text { Telemedicine } \\
\text { preferred }\end{array}$ \\
\hline High & Minimal & $\begin{array}{l}\text { Proceed for imminent } \\
\text { mortality airway } \\
\text { compromise, space- } \\
\text { critical metastases }\end{array}$ & $\begin{array}{l}\text { Considered on case by case } \\
\text { basis }\end{array}$ & $\begin{array}{l}\text { Cautious } \\
\text { initiation, } \\
\text { generally avoid } \\
\text { if ECOG }>1\end{array}$ & $\begin{array}{l}\text { Telemedicine } \\
\text { required }\end{array}$ \\
\hline
\end{tabular}

*Risk level: low-low community case load, low risk of patient having COVID and low risk of nosocomial acquisition; medium, moderate community case load; high-high community case load and high risk of community transmission AGP, aerosol generating procedures; VCC, vocal cord check.

(c) 2020 Society for Endocrinology Published by Bioscientifica Ltd. Printed in Great Britain 
The European Society of Medical Oncology (ESMO) guidelines for COVID-19 have highlighted two patient groups to consider, those 'off' therapy and those on 'active' therapy. Common to both groups are enforcing social distancing methods, PPE, and hand hygiene. In those on active treatment activities such as dispensing oral chemotherapy for 3 months at a time should be encouraged, delay follow up visits, telemedicine where possible and performing all pathology close to home to minimise nosocomial transfer (ESMO 2020). 'Active therapy' patients include newly diagnosed patients who need surgery and/or RAI; and patients with recurrent or metastatic disease. These patients will usually require physical attendance for assessment and treatment. 'Off active therapy' includes those DTC patients with low risk of recurrent and/or metastatic disease. These patients would be suitable for follow-up by virtual consultation. Patients with stable minimal residual disease might in selected cases also be managed by virtual consultation.

\section{Operating theatre and/or intensive care unit availability}

Thyroid cancer surgery is preferentially performed at specialist centres, with patients often having to travel from their homes to different locations, which may not be possible during the pandemic. In our institution, surgical clinic visits were reduced by approximately $80 \%$ during the height of our 'first wave' of COVID-19. In addition, surgical staff and/or operating theatres may be redeployed to manage COVID-19 cases. In Australia, elective surgery was furloughed to protect PPE availability until such a time as COVID-19 cases decreased and protect patients and staff from Aerosol generating procedures (AGP) and unintended exposure to COVID-19 (Brat et al. 2020). Surgery in the head and neck and intubation for anaesthesia is classified as a high risk of AGP and thus changes in theatre management have been introduced to mitigate this risk. These changes include the use of specialised PPE and changes to intubation protocols which have increased case time and further reduced theatre availability (Howard 2020).

In addition, the work-up of patients with thyroid cancer has changed with limited availability of vocal cord checks (VCC) using laryngoscopy due to the risk of generating aerosols in an uncontrolled environment, due to this in our institution, VCC were not able to be conducted for any patients including those with suspected vocal cord palsies (Thamboo et al. 2020).

Due to these issues, many surgical societies issued guidelines as to which patients should proceed with surgery, many of these guidelines divide presentation by urgency of the predicted harm if the patient's pathology was not treated (https://www.generalsurgeons.com.au/ covid-19). A common system used in Australia is to classify patients who will come to harm if surgery is delayed more than 4-6 weeks (Category 1) and those which will come to harm if delayed more than 12 weeks (Category 2), and cases assessed as being able to be delayed longer than 12 weeks (Category 3).

During the initial stages of the COVID-19 pandemic, only category 1 cases were recommended to proceed (Royal Australian College of Surgeons 2020).

Thus, patients with thyroid cancer were classified as Category 1 if the size and location of cancer posed an immediate threat of harm if left untreated; patients with smaller cancers were delayed. With the re-opening of semi-elective surgery in Australia, many of these patients with smaller cancers who were initially delayed have now been able to have surgery. However, a substantial number of patients with atypical nodules were delayed and who are only now proceeding with surgery for diagnostic hemithyroidectomy. It is likely that many patients have also delayed presentation for assessment and surgery, the effect of which will become apparent in the coming months to years.

\section{Availability of radioactive iodine resources}

Management of intermediate- and high-risk differentiated thyroid cancer includes post-surgical administration of I ${ }^{131}$. This usually requires admission to hospital, and thus there has been a decrease in nuclear medicine services for diagnosis (reduced by $58.4 \%$ for thyroid) and therapy (reduced by $41.8 \%$ ) noted in Europe after the pandemic has reached a peak (Freudenberg et al. 2020). Depending on the location, nuclear medicine procedures may also uncover asymptomatic patients with COVID-19, found in $9 \%$ of a series of asymptomatic patients in Italy in March 2020 (Albano et al. 2020). Local centres must carefully assess risk to patients with delay of diagnostic scans where possible, and mitigate risks of admission by risk assessment and utilize outpatient treatment where possible. The American Thyroid Association (ATA) has released guidelines on when it is possible to delay I ${ }^{131}$ and surgery for thyroid cancer, however, this largely depends on local COVID-19 transmission rates and the ability of the health systems to manage (American Thyroid Association 2020).

One additional point to note is the effect of $\mathrm{I}^{131}$ on smell. Olfactory function is reported to deteriorate in early c) 2020 Society for Endocrinology Published by Bioscientifica Ltd. Printed in Great Britain 
stages of I ${ }^{131}$ with mild and moderate anosmia occurring in the first year post I131 (Suat et al. 2016). Anosmia or hypoosmia is also a characteristic complication of COVID-19 (Gane et al. 2020). It is vital to recognise this crossover to avoid causing unnecessary alarm in patients following $\mathrm{I}^{131}$ treatment.

Overall, patient communication is critical to stratify risk and manage appropriately those with severe disease. Utilisation of telemedicine and continuation of remote multidisciplinary meetings will assist with difficult decision making (Hennessey 2020, Hollander \& Carr 2020). Although thyroid cancer is mostly slow growing, there are those with advanced disease whose prompt treatment should remain a priority despite the global pandemic (Wang \& Zhang 2020, Xia et al. 2020).

\section{Initiation and monitoring of tyrosine kinase inhibitor therapy}

Radioactive iodine refractory differentiated thyroid cancer and metastatic medullary thyroid cancer are often managed with tyrosine kinase inhibitor (TKI) systemic therapy, including lenvatinib, cabozatinib, and vandetanib (Gild et al. 2011, Wells et al. 2015, Haugen et al. 2016, Tsang et al. 2016). Treatment initiation even in non-pandemic times is challenging and when there is rapidly progressive disease a pandemic environment further complicates the situation. The decision to commence TKIs must balance the risks of regular clinic visits for clinical review, ECG and pathology tests on treatment, against the risk of cancer progression if left untreated. Generally, systemic therapy is recommended when patients develop symptomatic and/or progressive disease.

TKIs have a myriad of adverse effects, which usually present in the first few months of treatment (Cabanillas \& Takahashi 2019). They are well described and as such can be anticipated, monitored and managed remotely (Supplementary Table 1, see section on supplementary materials given at the end of this article). Of note, hypertension is common, and may be a positive sign that the patient will respond to treatment (Wirth et al. 2018). Ideally, patients should be provided with their own sphygmomanometer to monitor blood pressure remotely where possible and plan to escalate treatment within the first few weeks, including the use of increased doses of antihypertensive agents. The use of either angiotensinconverting enzyme inhibitors (ACEI) or angiotensin receptor blockers (ARB) appears to be safe in patients at risk for COVID-19 (Guo et al. 2020, Rico-Mesa et al. 2020, Vaduganathan et al. 2020, Zhang et al. 2020).
Other symptoms of TKIs can mimic COVID-19, including fatigue, nausea, vomiting, and diarrhoea. Palmar plantar erythrodysthesia is a common and often severe adverse effect, and having pre-emptive supply of potential treatment such as topical urea and corticosteroids may be useful to allow continuation of treatment. Use of smartphones to send clinicians high-resolution photographs of skin lesions may be a sensible method for follow up and assessing grades of severity. Some TKIs cause prolongation of the QT interval, particularly vandetanib. Utilisation of remote monitoring, such as with ECG apps on smartphones, may prompt earlier reviews where required (Garabelli et al. 2017).

As most follow up consultations will be by telemedicine, utilisation of prefilled adverse effects list prior to consultation will streamline the consultation (Supplementary Table 1).

\section{Heritable thyroid cancer syndromes}

As much as COVID-19 impacts on the practice of individual clinicians, its disruptive effects are magnified in conditions that require complex systems-based care. This is exemplified by the example of Multiple Endocrine Neoplasia syndrome type 2 (MEN2) and other heritable thyroid cancer syndromes. In ordinary circumstances, recognition and management of MEN2 follows a highly co-ordinated routine involving surgeons, physicians, pathologists, genetic testing facilities, family cancer centres, imaging facilities (both structural and PET) and, in some cases, fertility services. Thus, patients diagnosed with MTC should generally be referred for genetic counselling and germline RET testing; if MEN2 is confirmed, then cascade testing of first-degree relatives should be accompanied by appropriate genetic counselling. Familial RET mutation carriers will then be considered for prophylactic thyroidectomy (Wells et al. 2015); all MEN2 patients also require periodic screening for phaeochromocytoma (Brandi et al. 2001, Tsang et al. 2015, Wells et al. 2015). Prenatal counselling is appropriate for an MEN2 patient planning a family (Tsang et al. 2015). MEN2 patients with metastatic MTC may be suitable for targeted therapies.

COVID-19 will disrupt this 'supply chain' of MEN2 management at every step: patients with MTC may face delays in seeing a Genetics Service; RET genetic testing may be delayed due to reduced pathology services; family member tracing and testing will be compromised by disrupted Clinical Genetics services; referrals for prophylactic thyroidectomy will be delayed by restrictions 
on surgical services described previously; prenatal counselling may be more difficult to obtain; and diagnosis of metastatic MTC may be delayed if patients are reluctant to attend routine follow-up visits and/or oncology clinics and imaging facilities are restricted. These disruptions may have a multiplier effect on adverse outcomes: MEN2 may not be appropriately diagnosed; family members may not be traced and offered genetic testing; the benefits of prophylactic thyroidectomy may be lost; and metastatic disease may progress beyond the benefit of targeted therapy. There is no easy solution other than prioritising coordinated service delivery as best as possible.

\section{Impact of thyroid cancer on COVID-19}

\section{Increased risk of COVID-19 complications}

The initial data from Wuhan confirmed that harbouring malignancy increases the risk of ICU admission and death, HR 3.50 (95\% CI 1.60-7.64) (Guan et al. 2020).

\section{Predilection for thyroid cancer in COVID-19 patients}

To investigate a relationship between thyroid cancer and COVID-19, we examined first the effect of having thyroid cancer and the potential increased risk for COVID-19 acquisition and second, whether COVID-19 can predispose patients to cancers, including thyroid. As discussed above the spectrum of thyroid cancer patients is broad and those patients with small well-differentiated tumours are likely to do well regardless and these 'off active treatment' patients are unlikely to be immunosuppressed secondary to their cancer diagnosis. The 'active therapy' cohort thyroid cancer patients comprise immunocompromised cancer patients that are recognised to have an increased risk for community-acquired respiratory viruses (Whimbey et al. 1997). The cause of the increased risk is multifactorial, including cellular and humoral immunity compromise, invasive vascular lines and local tumour effects. It is estimated that patients with cancer are ten times more likely to acquire sepsis than those without (Thirumala et al. 2010). Indeed, a majority of thyroid cancer patients die from non-cancer related illnesses including infection (Zaorsky et al. 2017).

Treatment can further impact the likelihood of COVID-19 infection and complications. I $^{131}$ is used in both adjuvant and metastatic settings for DTC. $\mathrm{I}^{131}$ has short- and long-term effects on immune function that may affect patients' COVID-19 outcome. Transient reductions in myeloid and lymphoid cell lineages are common after ablative therapy which can continue out to 1 year (Molinaro et al. 2009). The nadir is usually 5-9 weeks. Bone marrow suppression following prolonged high dose I $^{131}$ is well described, and when used in conjunction with ERBT or in the presence of bony metastases it can lead to a more severe suppression (reviewed in Lee 2010). The CDC has indicated that patients with bone marrow suppression are at higher risk for COVID-19 severity and complications (US Department of Health \& Human Services 2020). I131 itself can modulate the immune system with cytokines dysregulation observed following I-131 treatment for Graves' disease (Du et al. 2017). In those thyroid cancer patients with thyroid autoimmunity, treatment with I131 can increase IL-6, a cytokine implicated in severe respiratory disease and death from COVID-19. Patients who did particularly poorly had a surge of IL- 6 and ferritin which correlated with mortality (Ruan et al. 2020).

It is controversial whether high-dose corticosteroids should be avoided in patients at risk of COVID-19. In previous coronavirus pandemics (MERS-CoV and SARS) corticosteroids were associated with worse outcomes in patients (Li et al. 2020). In thyroid cancer, corticosteroids are often used in patients with brain metastases or high volume lung metastases at the time of $\mathrm{I}^{131}$ treatment (McWilliams et al. 2003). From early data on COVID-19, some patients were found to be COVID-19 positive at the time of receiving $I^{131}$ therapy (Albano et al. 2020). All these issues whilst unknown could be considered in deciding timing of I $^{131}$ in the COVID-19 pandemic.

In the last decade, TKIs have become standard treatment for advanced thyroid cancers particularly those with anaplastic or radioiodine refractory components (Gild et al. 2017). Whether these agents increase the risk of COVID-19 infection and/or complications is unknown. Patients on lenvatinib in the SELECT trial were more likely to develop pneumonia, sepsis and other lower respiratory tract infections than the placebo group 6 (Schlumberger et al. 2015).

Drug interactions are also critical to consider for those on TKIs as the consequence can be fatal. Current experimental therapies for COVID-19 and potential thyroid cancer treatments interactions is Table 2 . Some TKIs used in the treatment of thyroid cancers including Dabrafenib, Trametinib and Selumetinib could be considered for repurposing as they have in vitro activity against other coronaviruses SARS and MERSCoV (Kindrachuk et al. 2015).

In our cancer patients, the decision to treat progressive metastatic disease must be balanced against the risk of 
Table 2 Interaction between COVID-19 and systemic thyroid cancer treatments.

\begin{tabular}{|c|c|}
\hline Treatment & Mechanism/theory \\
\hline Ivermectin & Inhibit viral repair \\
\hline Convalescent plasma & $\begin{array}{l}\text { IgG or IgM SARS-CoV-2 antibodies } \\
\text { as infusion }\end{array}$ \\
\hline Lopinavir-Ritonavir & Antiviral \\
\hline
\end{tabular}

Tocilzumab/Siltuximab Anti-IL6 receptor antibody Hydroxychloroquine Inhibited viral replication

ACE inhibitors

$$
\begin{aligned}
& \text { SARS-CoV2 binds to ACE2 } \\
& \text { receptor for cell entry }
\end{aligned}
$$

\begin{tabular}{l} 
Outcome \\
\hline Reduced viral cell RNA in vitro \\
Patients improved and viral load \\
negative \\
Mixed outcome, 1 study clinical \\
improvement, 2 nil
\end{tabular}

Reduced CRP levels in small group Effective in vitro and promising viral clearance in patients

Lower mortality
Thyroid cancer drug interaction

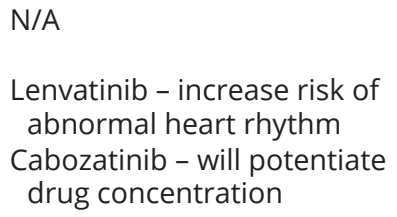

N/A

Lenvatinib - increase risk of abnormal heart rhythm Cabozatinib - will potentiate drug concentration

Nil reaction complications familiar to cancer patients such as infection compounded by frailty.

\section{Long-term risks}

Whether COVID-19 will ultimately lead to increased incidence of any cancer is highly speculative. However, viruses do play a role in the development of some cancers, including thyroid cancer. There is no data suggesting that other coronaviruses have affected thyroid cancer incidence, but these also had much lower worldwide infection rates compared with COVID-19. Certain viruses are established carcinogens including human papilloma virus, hepatitis $\mathrm{B}$ and $\mathrm{C}$ and Epstein Barr virus (EBV). EBV is a highly contagious and ubiquitous virus which can cause several cancers but the vast majority of those who contract it will have minor symptoms. EBV together with Parvovirus B19 have been associated with increased inflammation in thyroid tissue upregulating IL6 and TNFa and the presence of EBV and its gene products have also been associated with thyroid tumorigenesis (Etemadi et al. 2017, Moghoofei et al. 2019). EBV has also been shown to activate the ERK pathway which we know is dominant in thyroid cancer (Kakavandi et al. 2018). Whether this extends to COVID-19 is unknown nor the increase in incidence following prolonged COVID inflammation, an established cancer risk.

\section{Inflammation}

Infection leading to inflammation is an important consideration for the long-term effects of COVID-19. COVID-19 induces a proinflammatory generation and secretion of cytokines including IL-6. Chronic inflammation increases the risk and progression of cancer. Recent studies have shown how in a murine model, acute lung infection can augment tumour metastases by supporting a metastatic-niche like environment (Yan et al. 2013). Pneumonia with lung injury occurred in $16 \%$ of patients with SARS (Ruuskanen et al. 2011). Potential future effects of such widespread lung inflammation on our metastatic thyroid cancer patients is concerning and the extent unknown.

\section{Immunosuppression}

Long-term immunosuppression is linked with various complications including cancer incidence. In patients following renal transplants, there is a higher incidence of thyroid cancer thought to be due to the prolonged immunosuppression (Karamchandani et al. 2010, Veroux et al. 2019). The synchronous appearance of Hashimoto's thyroiditis and thyroid cancer has long connected a dysfunctional immune system with the development of malignancy (Ehlers \& Schott 2014). In other dysfunctional immune system diseases such as inflammatory bowel disease and SLE, thyroid cancer is more common and in those on immunosuppressive therapy had an increased risk (Antonelli et al. 2010, Cao 2018). Furthermore, the immunomodulatory effect of statins may also contribute to an increase in thyroid cancer prevalence in women in a case-control study (Hung et al. 2015).

\section{Academic setbacks}

The consequences for the thyroid cancer research community is grim and the impact on a thyroidologist is already lamented (Hennessey 2020). Several conferences have been postponed including the International Thyroid Congress, the Endocrine Society meeting in San Francisco, the ATA spring meeting. It is likely that more academic congresses in 2020 and beyond will be affected. The deceleration of research, and the lack of opportunity 
to share ideas in international meetings will take time to recover and regain momentum.

\section{Conclusions}

The impact of COVID-19 is unprecedented and this minireview aims to highlight the changes in risk management and practice for thyroid cancer. The generally indolent nature of many thyroid cancers may withstand delayed treatment, but this subtlety should be carefully communicated to patients. While we have attempted to anticipate some of the longer-term effects, vigilance is required in monitoring patients together with the frequently changing literature to remain up to date on the myriad of complications of this novel coronavirus.

\section{Supplementary materials}

This is linked to the online version of the paper at https://doi.org/10.1530/ ERC-20-0279.

\section{Declaration of interest}

$B$ R reports personal fees from Loxo Oncology, during the conduct of the study. B R, R C B and V T report personal fees from Eisai, outside the submitted work. The other authors report no conflict of interest.

\section{Funding}

This work did not receive any specific grant from any funding agency in the public, commercial, or not-for-profit sector.

\section{Author contribution statement}

All co-authors reviewed and approved the final manuscript.

\section{References}

Albano D, Bertagna F, Bertoli M, Bosio G, Lucchini S, Motta F, Panarotto MB, Peli A, Camoni L, Bengel FM, et al. 2020 Incidental findings suggestive of COVID-19 in asymptomatic patients undergoing nuclear medicine procedures in a high-prevalence region. Journal of Nuclear Medicine 61 632-636. (https://doi. org/10.2967/jnumed.120.246256)

American Thyroid Association 2020 Novel Coronarvirus (COVID-19) and the Thyroid: Frequently Asked Questions. Thyorid Nodules and Thyroid Cancer. Falls Church, VA, USA: ATA. (available at: https://www. thyroid.org/covid-19/coronavirus-frequently-asked-questions/)

Antonelli A, Mosca M, Fallahi P, Neri R, Ferrari SM, D’Ascanio A, Ghiri E, Carli L, Miccoli P \& Bombardieri S 2010 Thyroid cancer in systemic lupus erythematosus: a case-control study. Journal of Clinical Endocrinology and Metabolism 95 314-318. (https://doi.org/10.1210/ jc.2009-0677)
Bell SA, Banerjee M, Griggs JJ, Iwashyna TJ \& Davis MA 2020 The effect of exposure to disaster on cancer survival. Journal of General Internal Medicine 35 380-382. (https://doi.org/10.1007/s11606-019-05465-x)

Brandi ML, Gagel RF, Angeli A, Bilezikian JP, Beck-Peccoz P, Bordi C, Conte-Devolx B, Falchetti A, Gheri RG, Libroia A, et al. 2001 Guidelines for diagnosis and therapy of MEN type 1 and type 2. Journal of Clinical Endocrinology and Metabolism 86 5658-5671. (https://doi.org/10.1210/jcem.86.12.8070)

Brat GA, Hersey S, Chhabra K, Gupta A \& Scott J 2020 Protecting surgical teams during the COVID-19 outbreak: a narrative review and clinical considerations. Annals of Surgery [epub]. (https://doi. org/10.1097/SLA.0000000000003926)

Cabanillas ME \& Takahashi S 2019 Managing the adverse events associated with lenvatinib therapy in radioiodine-refractory differentiated thyroid cancer. Seminars in Oncology 46 57-64. (https:// doi.org/10.1053/j.seminoncol.2018.11.004)

Cabanillas ME, McFadden DG \& Durante C 2016 Thyroid cancer. Lancet 388 2783-2795. (https://doi.org/10.1016/S0140-6736(16)30172-6)

Cabanillas ME, Ryder M \& Jimenez C 2019 Targeted therapy for advanced thyroid cancer: kinase inhibitors and beyond. Endocrine Reviews 40 1573-1604. (https://doi.org/10.1210/er.2019-00007)

Cao L 2018 Assessment of thyroid cancer risk in more than 334,000 patients with inflammatory bowel disease: a case-control study and a meta-analysis. World Journal of Surgical Oncology 16 182. (https://doi. org/10.1186/s12957-018-1485-4)

Civantos FJ, Leibowitz JM, Arnold DJ, Stubbs VC, Gross JH, Thomas GR, Sargi Z, Casiano RR, Franzmann EJ, Weed D, et al. 2020 Ethical surgical triage of head and neck cancer patients during the COVID-19 pandemic. Head and Neck 42 1423-1447. (https://doi. org/10.1002/hed.26229)

Couloigner V, Schmerber S, Nicollas R, Coste A, Barry B, Makeieff M, Boudard P, Bequignon E, Morel N, Lescanne E, et al. 2020 COVID-19 and ENT surgery. European Annals of Otorhinolaryngology, Head and Neck Diseases 137 161-166. (https://doi.org/10.1016/j. anorl.2020.04.012)

Cui C, Yao Q, Zhang D, Zhao Y, Zhang K, Nisenbaum E, Cao P, Zhao K, Huang X, Leng D, et al. 2020 Approaching otolaryngology patients during the COVID-19 pandemic. Otolaryngology: Head and Neck Surgery 163 121-131. (https://doi.org/10.1177/0194599820926144)

Du W, Dong Q, Lu X, Liu X, Wang Y, Li W, Pan Z, Gong Q, Liang C \& Gao G 2017 Iodine-131 therapy alters the immune/inflammatory responses in the thyroids of patients with Graves' disease. Experimental and Therapeutic Medicine 13 1155-1159. (https://doi. org/10.3892/etm.2017.4047)

Ehlers M \& Schott M 2014 Hashimoto's thyroiditis and papillary thyroid cancer: are they immunologically linked? Trends in Endocrinology and Metabolism 25 656-664. (https://doi.org/10.1016/j.tem.2014.09.001)

ESMO 2020 COVID-19 and cancer. Lugano, Switzerland: ESMO. (available at: https://www.esmo.org/covid-19-and-cancer)

Etemadi A, Mostafaei S, Yari K, Ghasemi A, Minaei Chenar H \& Moghoofei M 2017 Detection and a possible link between parvovirus B19 and thyroid cancer. Tumour Biology 391010428317703634. (https://doi.org/10.1177/1010428317703634)

Freudenberg LS, Dittmer U \& Herrmann K 2020 Impact of COVID-19 on nuclear medicine in Germany, Austria and Switzerland: an International Survey in April 2020. Nuklearmedizin: Nuclear Medicine 59 294-299. (https://doi.org/10.1055/a-1163-3096)

Gane SB, Kelly C \& Hopkins C 2020 Isolated sudden onset anosmia in COVID-19 infection. A novel syndrome? Rhinology 58 299-301. (https://doi.org/10.4193/Rhin20.114)

Garabelli P, Stavrakis S \& Po S 2017 Smartphone-based arrhythmia monitoring. Current Opinion in Cardiology 32 53-57. (https://doi. org/10.1097/HCO.0000000000000350)

Gilbert AW, Billany JCT, Adam R, Martin L, Tobin R, Bagdai S, Galvin N, Farr I, Allain A, Davies L, et al. 2020 Rapid implementation of virtual clinics due to COVID-19: report and early evaluation of a quality
(C) 2020 Society for Endocrinology Published by Bioscientifica Ltd. Printed in Great Britain 
improvement initiative. BMJ Open Quality 9 e000985. (https://doi. org/10.1136/bmjoq-2020-000985)

Gild ML, Bullock M, Robinson BG \& Clifton-Bligh R 2011 Multikinase inhibitors: a new option for the treatment of thyroid cancer. Nature Reviews: Endocrinology 7 617-624. (https://doi.org/10.1038/ nrendo.2011.141)

Gild ML, Topliss DJ, Learoyd D, Parnis F, Tie J, Hughes B, Walsh JP, McLeod DSA, Clifton-Bligh RJ \& Robinson BG 2017 Clinical guidance for radioiodine refractory differentiated thyroid cancer. Clinical Endocrinology 88 529-537.

Grant EG, Tessler FN, Hoang JK, Langer JE, Beland MD, Berland LL, Cronan JJ, Desser TS, Frates MC, Hamper UM, et al. 2015 Thyroid ultrasound reporting lexicon: white paper of the ACR thyroid imaging, reporting and data system (TIRADS) committee. Journal of the American College of Radiology 12 1272-1279. (https://doi. org/10.1016/j.jacr.2015.07.011)

Greenhalgh T, Koh GCH \& Car J 2020 Covid-19: a remote assessment in primary care. BMJ $368 \mathrm{~m} 1182$. (https://doi.org/10.1136/bmj. m1182)

Guan WJ, Liang WH, Zhao Y, Liang HR, Chen ZS, Li YM, Liu XQ, Chen RC, Tang CL, Wang T, et al. 2020 Comorbidity and its impact on 1590 patients with Covid-19 in China: a nationwide analysis. European Respiratory Journal 55 2000547. (https://doi. org/10.1183/13993003.00547-2020)

Guo J, Huang Z, Lin L \& Lv J 2020 Coronavirus Disease 2019 (COVID$19)$ and cardiovascular disease: a viewpoint on the potential influence of angiotensin-converting enzyme inhibitors/angiotensin receptor blockers on onset and severity of severe acute respiratory syndrome coronavirus 2 infection. Journal of the American Heart Association 9 e016219. (https://doi.org/10.1161/JAHA.120.016219)

Haugen BR, Alexander EK, Bible KC, Doherty GM, Mandel SJ, Nikiforov YE, Pacini F, Randolph GW, Sawka AM, Schlumberger M, et al. 20162015 American Thyroid Association management guidelines for adult patients with thyroid nodules and differentiated thyroid cancer: the American Thyroid Association Guidelines Task Force on thyroid nodules and differentiated thyroid cancer. Thyroid 26 1-133. (https://doi.org/10.1089/thy.2015.0020)

Hennessey JV 2020 COVID-19 and how it is affecting me as a thyroidologist. Clinical Thyroidology 32 154-155. (https://doi. org/10.1089/ct.2020;32.154-155)

Hollander JE \& Carr BG 2020 Virtually perfect? Telemedicine for Covid19. New England Journal of Medicine 382 1679-1681. (https://doi. org/10.1056/NEJMp2003539)

Howard BE 2020 High-risk aerosol-generating procedures in COVID-19: respiratory protective equipment considerations. Otolaryngology: Head and Neck Surgery 163 98-103. (https://doi. org/10.1177/0194599820927335

Huang HL, Allie R, Gnanasegaran G \& Bomanji J 2020a COVID19 Nuclear Medicine Departments, be prepared! Nuclear Medicine Communications 41 297-299. (https://doi.org/10.1097/ MNM.0000000000001183)

Huang VW, Imam SA \& Nguyen SA $2020 b$ Head and neck survivorship care in the times of the SARS-CoV-2 pandemic. Head and Neck $\mathbf{4 2}$ 1664-1667. (https://doi.org/10.1002/hed.26235)

Hung SH, Lin HC \& Chung SD 2015 Statin use and thyroid cancer: a population-based case-control study. Clinical Endocrinology $\mathbf{8 3}$ 111-116. (https://doi.org/10.1111/cen.12570)

Kakavandi E, Shahbahrami R, Goudarzi H, Eslami G \& Faghihloo E 2018 Anoikis resistance and oncoviruses. Journal of Cellular Biochemistry 119 2484-2491. (https://doi.org/10.1002/jcb.26363)

Karamchandani D, Arias-Amaya R, Donaldson N, Gilbert J \& Schulte KM 2010 Thyroid cancer and renal transplantation: a meta-analysis. Endocrine-Related Cancer 17 159-167. (https://doi.org/10.1677/ERC09-0191)

Kidd M 2020 Australia's primary care COVID-19 response. Australian Journal of General Practice 49 [epub]. (https://doi.org/10.31128/AJGPCOVID-02)
Kindrachuk J, Ork B, Hart BJ, Mazur S, Holbrook MR, Frieman MB, Traynor D, Johnson RF, Dyall J, Kuhn JH, et al. 2015 Antiviral potential of ERK/MAPK and PI3K/AKT/mTOR signaling modulation for Middle East respiratory syndrome coronavirus infection as identified by temporal kinome analysis. Antimicrobial Agents and Chemotherapy 59 1088-1099. (https://doi.org/10.1128/AAC.03659-14)

Koo JR, Cook AR, Park M, Sun Y, Sun H, Lim JT, Tam C \& Dickens BL 2020 Interventions to mitigate early spread of SARS-CoV-2 in Singapore: a modelling study. Lancet: Infectious Diseases 20 678-688. (https://doi.org/10.1016/S1473-3099(20)30162-6)

Kooraki S, Hosseiny M, Myers L \& Gholamrezanezhad A 2020 Coronavirus (COVID-19) outbreak: what the Department of Radiology should know. Journal of the American College of Radiology 17 447-451. (https://doi.org/10.1016/j.jacr.2020.02.008)

Kowalski LP, Sanabria A, Ridge JA, Ng WT, de Bree R, Rinaldo A, Takes RP, Mäkitie AA, Carvalho AL, Bradford CR, et al. 2020 COVID19 pandemic: effects and evidence-based recommendations for otolaryngology and head and neck surgery practice. Head and Neck 42 1259-1267. (https://doi.org/10.1002/hed.26164)

Lee SL 2010 Complications of radioactive iodine treatment of thyroid carcinoma. Journal of the National Comprehensive Cancer Network $\mathbf{8}$ 1277-1287; quiz 1287. (https://doi.org/10.6004/jnccn.2010.0094)

Li H, Chen C, Hu F, Wang J, Zhao Q, Gale RP \& Liang Y 2020 Impact of corticosteroid therapy on outcomes of persons with SARS-CoV-2, SARS-CoV, or MERS-CoV infection: a systematic review and metaanalysis. Leukemia 34 1503-1511. (https://doi.org/10.1038/s41375020-0848-3)

Liang W, Guan W, Chen R, Wang W, Li J, Xu K, Li C, Ai Q, Lu W, Liang $\mathrm{H}$, et al. 2020 Cancer patients in SARS-CoV-2 infection: a nationwide analysis in China. Lancet: Oncology 21 335-337. (https:// doi.org/10.1016/S1470-2045(20)30096-6)

Man RX, Lack DA, Wyatt CE \& Murray V 2018 The effect of natural disasters on cancer care: a systematic review. Lancet: Oncology 19 e482-e499. (https://doi.org/10.1016/S1470-2045(18)30412-1)

McWilliams RR, Giannini C, Hay ID, Atkinson JL, Stafford SL \& Buckner JC 2003 Management of brain metastases from thyroid carcinoma: a study of 16 pathologically confirmed cases over 25 years. Cancer 98 356-362. (https://doi.org/10.1002/cncr.11488)

Mick P \& Murphy R 2020 Aerosol-generating otolaryngology procedures and the need for enhanced PPE during the COVID-19 pandemic: a literature review. Journal of Otolaryngology: Head and Neck Surgery 49 29. (https://doi.org/10.1186/s40463-020-00424-7)

Moghoofei M, Mostafaei S, Nesaei A, Etemadi A, Sadri Nahand J, Mirzaei H, Rashidi B, Babaei F \& Khodabandehlou N 2019 EpsteinBarr virus and thyroid cancer: the role of viral expressed proteins. Journal of Cellular Physiology 234 3790-3799. (https://doi. org/10.1002/jcp.27144)

Molinaro E, Leboeuf R, Shue B, Martorella AJ, Fleisher M, Larson S \& Tuttle RM 2009 Mild decreases in white blood cell and platelet counts are present one year after radioactive iodine remnant ablation. Thyroid 19 1035-1041. (https://doi.org/10.1089/thy.2008.0430)

Perrier ND, Brierley JD \& Tuttle RM 2018 Differentiated and anaplastic thyroid carcinoma: major changes in the American Joint Committee on cancer eighth edition cancer staging manual. CA: A Cancer Journal for Clinicians 68 55-63. (https://doi.org/10.3322/caac.21439)

Rico-Mesa JS, White AAnderson AS \& 2020 Outcomes in patients with COVID-19 infection taking ACEI/ARB. Current Cardiology Reports 2231.

Royal Australian College of Surgeons 2020 RACS Guidelines for the Management of Surgical Patients during the COVID-19 Pandemic. Melbourne, Australia: Royal Australian College of Surgeons. (available at: https://www.surgeons.org/-/media/Project/RACS/surgeons-org/files/ news/covid19-information-hub/racs-guidelines-for-the-managementof-surgical-patients-during-the-covid19-pandemic.pdf)

Ruan Q, Yang K, Wang W, Jiang L \& Song J 2020 Clinical predictors of mortality due to COVID-19 based on an analysis of data of 150 patients from Wuhan, China. Intensive Care Medicine 46 846-848. (https://doi.org/10.1007/s00134-020-05991-x) 
Ruuskanen O, Lahti E, Jennings LC \& Murdoch DR 2011 Viral pneumonia. Lancet 377 1264-1275. (https://doi.org/10.1016/S01406736(10)61459-6)

Schlumberger M, Tahara M, Wirth LJ, Robinson B, Brose MS, Elisei R, Habra MA, Newbold K, Shah MH, Hoff AO, et al. 2015 Lenvatinib versus placebo in radioiodine-refractory thyroid cancer. New England Journal of Medicine 372 621-630. (https://doi.org/10.1056/ NEJMoa1406470)

Suat B, Deniz Tuna E, Ozgur Y, Muhammet Y \& Tevfik C 2016 The effects of radioactive iodine therapy on olfactory function. American Journal of Rhinology and Allergy 30 206-210. (https://doi.org/10.2500/ ajra.2016.30.4384)

Thamboo A, Lea J, Sommer DD, Sowerby L, Abdalkhani A, Diamond C, Ham J, Heffernan A, Cai Long M, Phulka J, et al. 2020 Clinical evidence based review and recommendations of aerosol generating medical procedures in otolaryngology - head and neck surgery during the COVID-19 pandemic. Journal of Otolaryngology: Head and Neck Surgery 49 28. (https://doi.org/10.1186/s40463-020-00425-6)

Thirumala R, Ramaswamy M \& Chawla S 2010 Diagnosis and management of infectious complications in critically ill patients with cancer. Critical Care Clinics 26 59-91. (https://doi.org/10.1016/j.ccc.2009.09.007)

Tsang VH, Tacon LJ, Learoyd DL \& Robinson BG 2015 Pheochromocytomas in multiple endocrine neoplasia type 2. Recent Results in Cancer Research 204 157-178. (https://doi.org/10.1007/9783-319-22542-5_7)

Tsang VH, Robinson BG \& Learoyd DL 2016 The safety of vandetanib for the treatment of thyroid cancer. Expert Opinion on Drug Safety 15 1107-1113. (https://doi.org/10.1080/14740338.2016.1201060)

US Department of Health \& Human Services 2020 Groups at Higher Risk for Severe Illness. Atlanta, GA, USA: Center for Disease Control and Prevention. (available at: https://www.cdc.gov/coronavirus/2019ncov/need-extra-precautions/people-at-increased-risk.html)

Vaduganathan M, Vardeny O, Michel T, McMurray JJV, Pfeffer MA \& Solomon SD 2020 Renin-angiotensin-aldosterone system inhibitors in patients with Covid-19. New England Journal of Medicine 382 1653-1659. (https://doi.org/10.1056/NEJMsr2005760)

Veroux M, Giuffrida G, Lo Bianco S, Cannizzaro MA, Corona D, Giaquinta A, Palermo C, Carbone F, Carbonaro A, Cannizzaro MT, et al. 2019 Thyroid disease and cancer in kidney transplantation: a single-center analysis. BMC Surgery 18 80. (https://doi.org/10.1186/ s12893-018-0408-1)

von Lilienfeld-Toal M, Vehreschild JJ, Cornely O, Pagano L, Compagno F, EHA Infectious Disease Scientific Working Group \& Hirsch HH 2020 Frequently asked questions regarding SARS-CoV-2 in cancer patients-recommendations for clinicians caring for patients with malignant diseases. Leukemia 34 1487-1494. (https://doi. org/10.1038/s41375-020-0832-y)

Vrachimis A, Iakovou I, Giannoula E \& Giovanella L 2020 ENDOCRINOLOGY IN THE TIME OF COVID-19: Management of thyroid nodules and cancer. European Journal of Endocrinology 183 G41-G48. (https://doi.org/10.1530/EJE-20-0269)

Wang H \& Zhang L 2020 Risk of COVID-19 for patients with cancer. Lancet: Oncology 21 e181. (https://doi.org/10.1016/S14702045(20)30149-2)

Wang Z, Yang B, Li Q, Wen L \& Zhang R 2020 Clinical features of 69 cases with coronavirus disease 2019 in Wuhan, China. Clinical Infectious Diseases 71 769-777. (https://doi.org/10.1093/cid/ciaa272)

Wells Jr SA, Asa SL, Dralle H, Elisei R, Evans DB, Gagel RF, Lee N, Machens A, Moley JF, Pacini F, et al. 2015 Revised American Thyroid Association guidelines for the management of medullary thyroid carcinoma. Thyroid 25 567-610. (https://doi.org/10.1089/ thy.2014.0335)

Whimbey E, Englund JA \& Couch RB 1997 Community respiratory virus infections in immunocompromised patients with cancer. American Journal of Medicine 102 10-18; discussion 25-16. (https://doi. org/10.1016/s0002-9343(97)80004-6)

Wirth LJ, Tahara M, Robinson B, Francis S, Brose MS, Habra MA, Newbold K, Kiyota N, Dutcus CE, Mathias E, et al. 2018 Treatmentemergent hypertension and efficacy in the phase 3 study of (E7080) lenvatinib in differentiated cancer of the thyroid (SELECT). Cancer 124 2365-2372. (https://doi.org/10.1002/cncr.31344)

Xia Y, Jin R, Zhao J, Li W \& Shen H 2020 Risk of COVID-19 for patients with cancer. Lancet: Oncology 21 e180. (https://doi.org/10.1016/ S1470-2045(20)30150-9)

Yan L, Cai Q \& Xu Y 2013 The ubiquitin-CXCR4 axis plays an important role in acute lung infection-enhanced lung tumor metastasis. Clinical Cancer Research 19 4706-4716. (https://doi. org/10.1158/1078-0432.CCR-13-0011)

Zaorsky NG, Churilla TM, Egleston BL, Fisher SG, Ridge JA, Horwitz EM \& Meyer JE 2017 Causes of death among cancer patients. Annals of Oncology 28 400-407. (https://doi.org/10.1093/ annonc/mdw604)

Zhang P, Zhu L, Cai J, Lei F, Qin JJ, Xie J, Liu YM, Zhao YC, Huang X, Lin L, et al. 2020 Association of inpatient use of angiotensin converting enzyme inhibitors and angiotensin II receptor blockers with mortality among patients with hypertension hospitalized with COVID-19. Circulation Research 126 1671-1681. (https://doi. org/10.1161/CIRCRESAHA.120.317134)

Received in final form 10 August 2020

Accepted 18 August 2020

Accepted Manuscript published online 18 August 2020
C) 2020 Society for Endocrinology Published by Bioscientifica Ltd. Printed in Great Britain 